\title{
Integrative Genomics: In Silico Coupling of Rat Physiology and Complex Traits With Mouse and Human Data
}

\author{
Simon N. Twigger, ${ }^{1,2,5}$ Jeff Nie, ${ }^{1}$ Victor Ruotti, ${ }^{1}$ Jiaming Yu, ${ }^{1}$ Dan Chen, ${ }^{1,3}$ Dawei Li, ${ }^{1}$ \\ Jed Mathis, ${ }^{1}$ Vijay Narayanasamy, ${ }^{1}$ Gopal R. Gopinath, ${ }^{1,4}$ Dean Pasko, ${ }^{1}$ \\ Mary Shimoyama, ${ }^{1}$ Norberto de la Cruz, ${ }^{1}$ Susan Bromberg, ${ }^{1}$ Anne E. Kwitek, ${ }^{1,2}$ \\ Howard J. Jacob, ${ }^{1,2}$ and Peter J. Tonellato ${ }^{1,2}$ \\ ${ }^{1}$ Human and Molecular Genetics Center and ${ }^{2}$ Department of Physiology, Medical College of Wisconsin, \\ Milwaukee, Wisconsin 53226, USA
}

\begin{abstract}
Integration of the large variety of genome maps from several organisms provides the mechanism by which physiological knowledge obtained in model systems such as the rat can be projected onto the human genome to further the research on human disease. The release of the rat genome sequence provides new information for studies using the rat model and is a key reference against which existing and new rat physiological results can be aligned. Previously, we described comparative maps of the rat, mouse, and human based on EST sequence comparisons combined with radiation hybrid maps. Here, we use new data and introduce the Integrated Genomics Environment, an extensive database of curated and integrated maps, markers, and physiological results. These results are integrated by using VCMapview, a java-based map integration and visualization tool. This unique environment allows researchers to relate results from cytogenetic, genetic, and radiation hybrid studies to the genome sequence and compare regions of interest between human, mouse, and rat. Integrating rat physiology with mouse genetics and clinical results from human by using the respective genomes provides a novel route to capitalize on comparative genomics and the strengths of model organism biology.
\end{abstract}

The release of the draft Rattus norvegicus genome opens the way for the rat to make further contributions as a model organism of complex human diseases. Known as the preeminent model system for physiological and complex disease studies, there exists substantial literature describing the use of the rat in elucidating physiological mechanisms and factors contributing to complex diseases, their symptoms, and phenotypes (for review, see Jacob and Kwitek 2002). Now, researchers are anxious to translate these results into a context more easily applied to human. Besides its obvious importance to basic science and molecular genetics, the rat genome enables this translation through an in silico process we refer to as integrative genomics. We have exploited this process to integrate analyses, data sets, and a map viewer (VCMapView) to create the Integrated Genomics Environment (IGE) that links various maps within and between species. The addition of the rat genome to that of human and mouse provides a third and vital contribution to the genomic "text" and, with IGE, adds a substantial knowledge base of the pharmacology, physiology, and mechanisms important to complex human diseases.

Studies of complex multifactorial diseases such as cancer, hypertension, diabetes, and obesity along with the physiology, mechanisms, and related phenotypes in the rat have necessitated the creation of a variety of mapping resources. Genetic mapping experiments use phenotype and genotype variation and recom-

Present addresses: ${ }^{3}$ PointOne Systems, LLC, Milwaukee, Wisconsin, USA; ${ }^{4}$ Cold Spring Harbor Laboratory, Cold Spring Harbor, New York, USA

${ }^{5}$ Corresponding author.

E-MAIL simont@mcw.edu; FAX (414) 456-6595.

Article and publication are at http://www.genome.org/cgi/doi/10.1101/ gr.1974504. bination to identify the location of genetic influence of these diseases. These locations, or 'quantitative trait loci' (QTL), exist for a wide variety of phenotypes - the Rat Genome Database (RGD) has curated records for 563 unique QTLs representing $>60$ unique phenotypes (Twigger et al. 2002). QTLs represent regions of the genome cosegregating with the trait of interest and hence are highly likely to contain candidate gene(s) important to the expression of the phenotype (for review, see Rapp 2000). QTL results are cross and strain specific because the studies require a genetic map of polymorphic markers; consequently, the creation, use, and integration of genetic maps and associated results remained a formidable challenge until radiation hybrid $(\mathrm{RH})$ mapping was developed (Cox et al. 1990).

Several RH maps have been published for the rat (Steen et al. 1999; Watanabe et al. 1999; McCarthy et al. 2000; Scheetz et al. 2001), and we announce an updated version of the MCW RH genome map that doubles the number of elements on the map in a companion paper in this journal (Kwitek et al. 2004). The power of RH mapping is the ability to map anything for which a unique set of primers can be designed and specifically amplified in rat. This approach removes the requirement for "polymorphism" and results in numerous genes and sequences being mapped onto the genome (see al-Majali et al. 1999; Gosele et al. 2000; Schulz et al. 2000; Avner et al. 2001; Laes et al. 2001; Szpirer et al. 2001; Tseng et al. 2001, 2002; Behboudi et al. 2002; Dobbins et al. 2002; Wallace et al. 2002). Online map servers (Rat Radiation Hybrid Mapserver; http://ratmap.ims.u-tokyo.ac.jp/ cgi-bin/RH/rhNgv.pl), which take PCR results as input and return a map location referenced to a common framework map, have removed the need for laboratories to undertake their own largescale mapping projects. Construction of framework maps offers an additional advantage; they provide the anchors that can be 
used to "virtually" reference investigator's results to the rat, human, and mouse genome resources.

Rat genome mapping has progressed from somatic cell hybrids (Szpirer et al. 1984) and cytogenetic localization, to genetic and $\mathrm{RH}$ maps and now to the rat genomic sequence. With each development, much effort has been expended to integrate and reference the resulting maps: genetic (Brown et al. 1998; Remmers et al. 1999; Dracheva et al. 2000); genetic with RH (Steen et al. 1999; Bihoreau et al. 2001); and cytogenetic, genetic, and RH (Szpirer et al. 1997, 1998, 1999; Kitada et al. 2000; Behboudi et al. 2002). Comparative integration between human and mouse maps has been similarly popular (examples include Marino et al. 1986; Szpirer et al. 1990, 2000; Yamada et al. 1994; Kuroiwa et al. 1998; Serikawa et al. 1998; Hornum and Markholst 2000; Kaisaki et al. 2000; Kwitek et al. 2001; Nilsson et al. 2001). In addition to the genome-wide integration efforts, many investigators use synteny between genomes to compare regions of interest (such as a QTLs) across human, rat, mouse, and other organisms. These substantial efforts reflect the importance of integration and comparative mapping to the model organ-

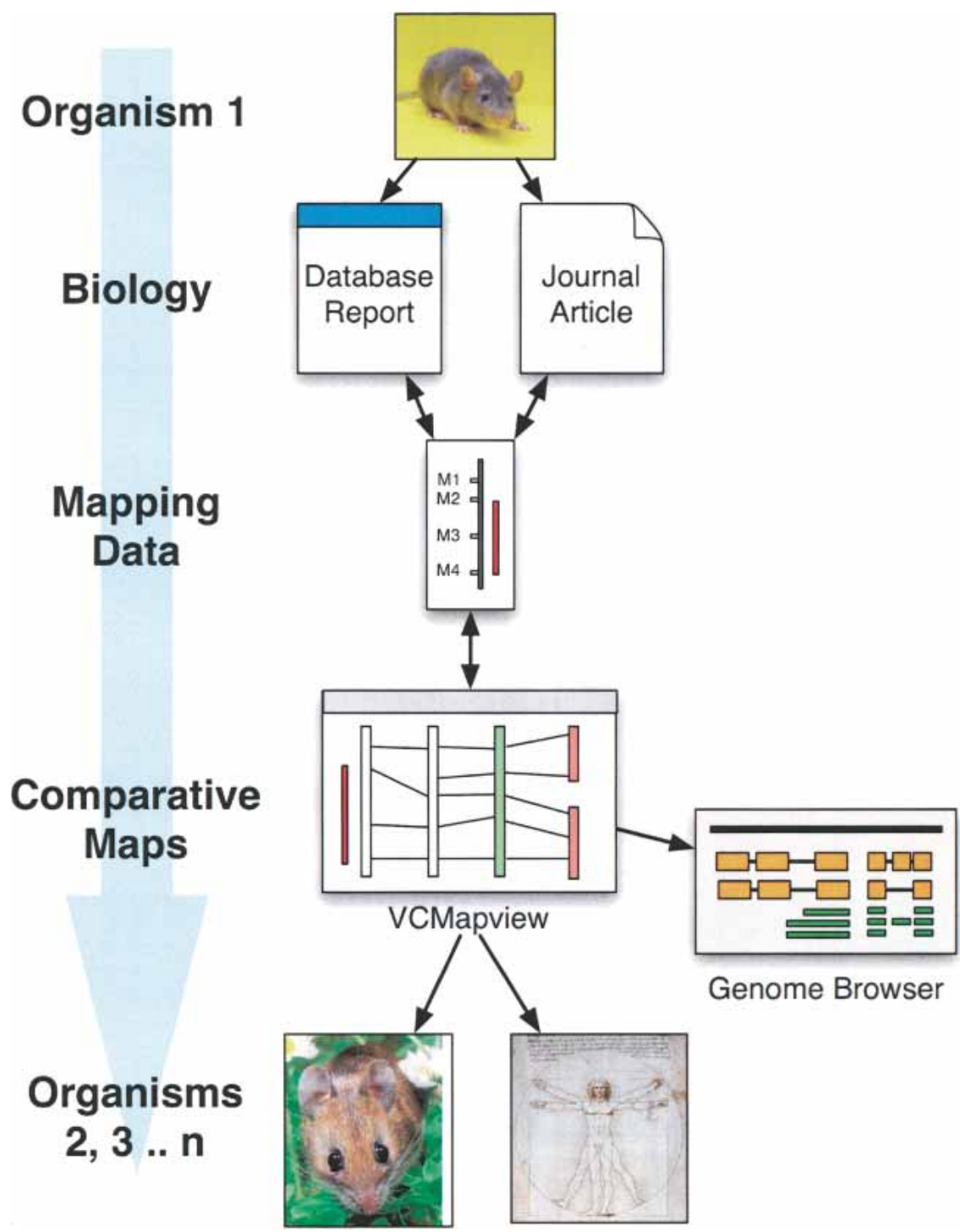

Figure 1 The Integrated Physiological Genomics Environment and VCMapView support a comparative strategy, allowing the biology mapped to organism one (e.g., QTLs, genes) to be translated to the genome and to syntenic regions in organisms 2 and 3 via the comparative maps ism community. With the release of the rat genomic sequence, integration of previous studies with these new resources is essential to support this vital need of the research community.

Sequence-level genome review tools are available from Ensembl (Clamp et al. 2003), UCSC (Karolchik et al. 2003), GMOD (Stein et al. 2002), and Genboree (http://www.genboree.org). Users can view details of one organism's genome and annotations ranging from 10 s to millions of bases of genomic sequence. Annotations are shown in the form of horizontal tracks displayed or hidden as desired. Sequence level comparative analysis tools (e.g., Vista [Couronne et al. 2003] and PipMaker [Schwartz et al. 2000]) also provide user-friendly environments to peruse horizontally arrayed analytical results of sequence alignments across organisms. These tools are superb at viewing detailed gene and genome loci annotations. However, these resources do not provide an effective environment for integration and navigation of the entire spectrum of maps (cytogenetic, genetic, RH, and genome sequence) used for the physiology and disease research in experimental models and human. Other resources exist at other databases that integrate some of this data by using conventional static pages; for example, Ratmap provides static linkage group orientation pages connecting rat cytogenetic map locations to mapped genes and markers (http://ratmap.gen.gu.se/ Orient.html), NCBI's mapview tool (http:// www.ncbi.nlm.nih.gov/mapview/static/ MVstart.html) has very extensive map lists and is very well suited to exploring multiple maps for a single organism. One major problem to overcome is the wide range in resolution between the sequence and the biology mapped onto it. Our goal was to develop a new environment that provided a means to integrate the wide spectrum of diverse maps to provide annotation of physiological traits and complex disease traits (QTLs) in rat, mouse, and human and thus build an integrative genomics environment.

We have developed a novel powerful integrative mapping environment with markers, maps, and annotations; a database of the maps, markers, and physiological results; and an in silico cross-organism mapping tool (VCMapView) to address these issues. VCMapView allows an investigator to navigate from map to map, genome to genome, and thus uniquely combines and visualizes distinctive information linked to each type of map. In particular, it enables a powerful strategy to link physiologically important and genetically influenced phenotypes, which can, via their QTL positions, be displayed and traced from genetic maps to genomic sequence and thus linked immediately to genome browsers for review of sequence-level candidate gene annotations (Fig. 1). As such, the IGE is a unique and powerful tool/environment for investigators to translate results from rat physiological research to the molecular genetics of mouse studies and simultaneously into the clinical context of the human genome. The IGE environment and VCMapView tool are available on the RGD at http:// rgd.mcw.edu/VCMAP/.

\section{Genome Research} www.genome.org 


\section{RESULTS}

\section{Markers and Maps}

A total of 17 distinct genetic, cytogenetic, and $\mathrm{RH}$ maps and related genome annotations have been integrated into the VCMapView database (for complete list, see Table 1), with a further six annotation maps available that show QTLs and cytogenetic features linked to one of the 17 distinct maps. More mapped rat markers $(31,136)$ are contained in VCMapView than in any other single browser environment. Similarly, 44,185 mouse markers and 152,980 human markers are represented. In total, this provides 228,301 mapped markers from the three species integrated into a single searchable cross-mapped environment, providing investigators with an enormously powerful search, exploration, and discovery resource. In addition, 111,064 human, 90,444 mouse, and 63,253 rat UniGene clusters are represented, which nearly quadruples the number of ESTs, sequences, and Unigenes available in our previous static release (Table 2.)

\section{Intraorganism Maps}

Of the 23 maps, nine are rat, nine are human, and five are from previous mouse studies. As described above, genetic mapping studies have provided the bulk of historical data linking phenotypes to genes or genomic regions; consequently, these genes or regions are typically identified by specific microsatellite markers placed on these genetic maps. However, because genetic mapping relies on a detectable polymorphism in order to be able to locate a marker via a genetic cross, this reduces the number of markers that can be placed on even the best genetic maps (Table 1). Marker density becomes a problem when trying to narrow regions of interest and when trying to compare genetic maps made with non-overlapping marker sets (not all markers that are polymorphic in one mapping cross will be polymorphic in another cross). The solution to this problem is to relate the genetic maps to a more densely populated map such as the $\mathrm{RH}$ or the genome. The maps available in the IGE are listed under seven separate headings-Comparative maps, Radiation Hybrid, Cyto- genetic, Genetic, Genome, QTL, and Additional. A simple interface is provided to allow the user to select any combination of maps for display. Once loaded into the java environment, more controls are provided to modify the display to show or hide connections between maps and specific markers and annotations.

\section{Interorganism Maps}

A general cross-organism analysis using $\mathrm{RH}$ maps of rat, mouse, and human to create a set of results that allows integration of annotated results across organisms was previously published (Kwitek et al. 2001). Our latest build of these comparative maps using recent UniGene and sequence data has double the number of mapped markers (Kwitek et al. 2004), which doubles the resolution of the comparative component of the IGE (Table 2). VCMapview can be used to visualize the core comparative relationships (Fig. 2), and this has been further enhanced by the availability within the IGE of key cytogenetic and genetic cross maps and the genome sequences for rat, human, and mouse

\section{Mapping of Physiological Traits}

Of 563 rat QTLs curated by the RGD project (total as of December 2003), 359 had one or more of their primary flanking or peak markers mapped on the new RH map (version 3.4) thereby allowing the QTLs to be integrated onto a single map. In comparison, only 219 QTLs could be located by using markers mapped on the current genome build because many microsatellite markers are unable to be mapped at high enough confidence using in silico mapping techniques such as BLAT and ePCR. QTLs with both flanking markers mapped could be positioned exactly on the RH map. In situations in which only the peak of the QTL or one flanking marker was available in addition to the peak location, an algorithm was used to conservatively predict the location of the second flanking marker to allow the span of the QTL to be depicted. All curated RGD QTLs were incorporated into the study database, and of these, 151 represent phenotypes exhibited in hypertension, 78 from type I and type II diabetes, 59 from arthritis studies, and the remainder from quantitative traits associated with obesity, renal disease, cardiovascular disease, and

Table 1. List of Available Maps Available in the Integrated Genomic Environment

\begin{tabular}{|c|c|c|c|c|}
\hline Organism & Map type & Description & Number of markers & Reference \\
\hline \multirow[t]{9}{*}{ Rat } & Genetic & $\mathrm{FHH} \times \mathrm{ACl}$ & 2083 & Steen et al. 1999 \\
\hline & Genetic & SHRSP $\times$ BN & 3824 & Steen et al. 1999 \\
\hline & $\mathrm{RH}$ & MCW version 2.1 & 10,733 & Steen et al. 1999 \\
\hline & $\mathrm{RH}$ & MCW version 3.4 & 24,437 & Kwitek et al. 2004 \\
\hline & Genome & MCW annotation of Build 3.1 & 27,389 & See Methods \\
\hline & Virtual & VCMap Build 8.6 & & Kwitek et al. 2001 \\
\hline & QTL & RGD Q'TLs linked to RH version 3.4 & 359 QTL & See Methods \\
\hline & QTL & RGD QTLs linked to Genome, version 3.1 & 219 QTL & See Methods \\
\hline & Cytogenetic & Cytogenetic bands and mapped genes & 3,565 & See Methods \\
\hline \multirow[t]{5}{*}{ Mouse } & Genetic & $\mathrm{MGl}$ & 15,667 & Blake et al. 2003 \\
\hline & $\mathrm{RH}$ & WI/MIT R9 & 10,898 & Hudson et al. 2001 \\
\hline & Genome & UCSC annotation from February 2003 build & 36,736 & Karolchik et al. 2003 \\
\hline & Virtual & VCMap Build 8.6 & & Kwitek et al. 2001 \\
\hline & QTL & MGD QTL & 1,461 QTL & See Methods \\
\hline \multirow[t]{9}{*}{ Human } & Genetic & Marshfield sex averaged & 8,010 & Broman et al. 1998 \\
\hline & Genetic & Marshfield male & 8,010 & Broman et al. 1998 \\
\hline & Genetic & Marshfield female & 8,010 & Broman et al. 1998 \\
\hline & Genetic & Genethon & 5,264 & Dib et al. 1996 \\
\hline & $\mathrm{RH}$ & Genemap99 & 45,756 & Deloukas et al. 1998 \\
\hline & $\mathrm{RH}$ & Genemap98 & 38,322 & Deloukas et al. 1998 \\
\hline & Genome & UCSC annotation from April 2003 build & 150,046 & Karolchik et al. 2003 \\
\hline & Virtual & VCMap Build 8.6 & & Kwitek et al. 2001 \\
\hline & Cytogenetic & Human cytogenetic bands plus OMIM morbid map & 8755 & McKusick and Amberger 1993 \\
\hline
\end{tabular}

This is a comprehensive list of maps available at the time of submission. Additional maps can be suggested/submitted for inclusion on the public site; please contact RGD User Support (http://rgd.mcw.edu/contact/). 
Twigger et al.

Table 2. Comparison of Mapped Markers and Unigenes Used in the Creation of Integrative Map Version 5.0 (Kwitek et al. 2001) With Those Used in the Current Map (Version 8.6)

\begin{tabular}{|c|c|c|c|c|c|c|c|c|}
\hline & \multicolumn{2}{|c|}{ Unigenes } & \multicolumn{2}{|c|}{ Sequences } & \multicolumn{2}{|c|}{$\begin{array}{l}\text { Mapped ESTs } \\
(\text { RH panel) }\end{array}$} & \multicolumn{2}{|c|}{$\begin{array}{l}\text { Unigene Build } \\
\text { (date of build) }\end{array}$} \\
\hline & 2001 & 2003 & 2001 & 2003 & 2001 & 2003 & 2001 & 2003 \\
\hline Human & 81,979 & 111,064 & $1,677,192$ & $4,135,222$ & $\begin{array}{c}45,741 \\
(\mathrm{~GB} 4)\end{array}$ & $\begin{array}{c}45,756 \\
\text { (GB4) }\end{array}$ & $\begin{array}{c}115 \\
(6 / 28 / 00)\end{array}$ & $\begin{array}{c}160 \\
(5 / 20 / 03)\end{array}$ \\
\hline Mouse & 87,512 & 90,444 & 894,559 & $3,442,382$ & $\begin{array}{l}2,158 \\
\text { (T31) } \\
\text { MGC }\end{array}$ & $\begin{array}{c}10,898 \\
\text { (T31) } \\
\text { MGC }\end{array}$ & $\begin{array}{c}78 \\
(6 / 28 / 00)\end{array}$ & $\begin{array}{c}120 \\
(5 / 20 / 03)\end{array}$ \\
\hline Rat & 36,953 & 63,253 & 173,027 & 346,154 & $\begin{array}{l}6,102 \\
(\mathrm{~T} 55)\end{array}$ & $\begin{array}{c}18,849 \\
(T 55)\end{array}$ & $\begin{array}{c}77 \\
(6 / 28 / 00)\end{array}$ & $\begin{array}{c}116 \\
(5 / 20 / 03)\end{array}$ \\
\hline
\end{tabular}

Unigene and EST information as reported by NCBI

(http://www.ncbi.nlm.nih.gov/UniGene/). Human map information is from GeneMap99 (http://www.ncbi.nlm.nih.gov/genemap99/). Mouse map information is from the Mouse Genome Center (MGC; http://websql.har.mrc.uk/). Rat map information is from RGD (http://rgd.mcw.edu/MAPS/; Steen et al. 1999).

other autoimmune diseases. The maps available in the IGE can be used to visualize QTLs alongside a wide variety of additional data linked to other maps in the same organism. This allows researchers to answer questions such as "What genes lie on the genomic sequence within this QTL region, and how do they relate to the cytogenetic map data?" (Fig. 3). In addition to the rat QTLs, 1402 mouse QTLs collected from the Mouse Genome Database (MGD; Blake et al. 2003) with corresponding referenced mapped markers were also integrated into the environment, allowing crossorganism disease phenotype testing. As there is no central repository for human QTL results, we have included the OMIM Morbid Map data set linked to the human cytogenetic map (McKusick and Amberger 1993). The morbid map contains the mapping information for the curated disease genes described in Online

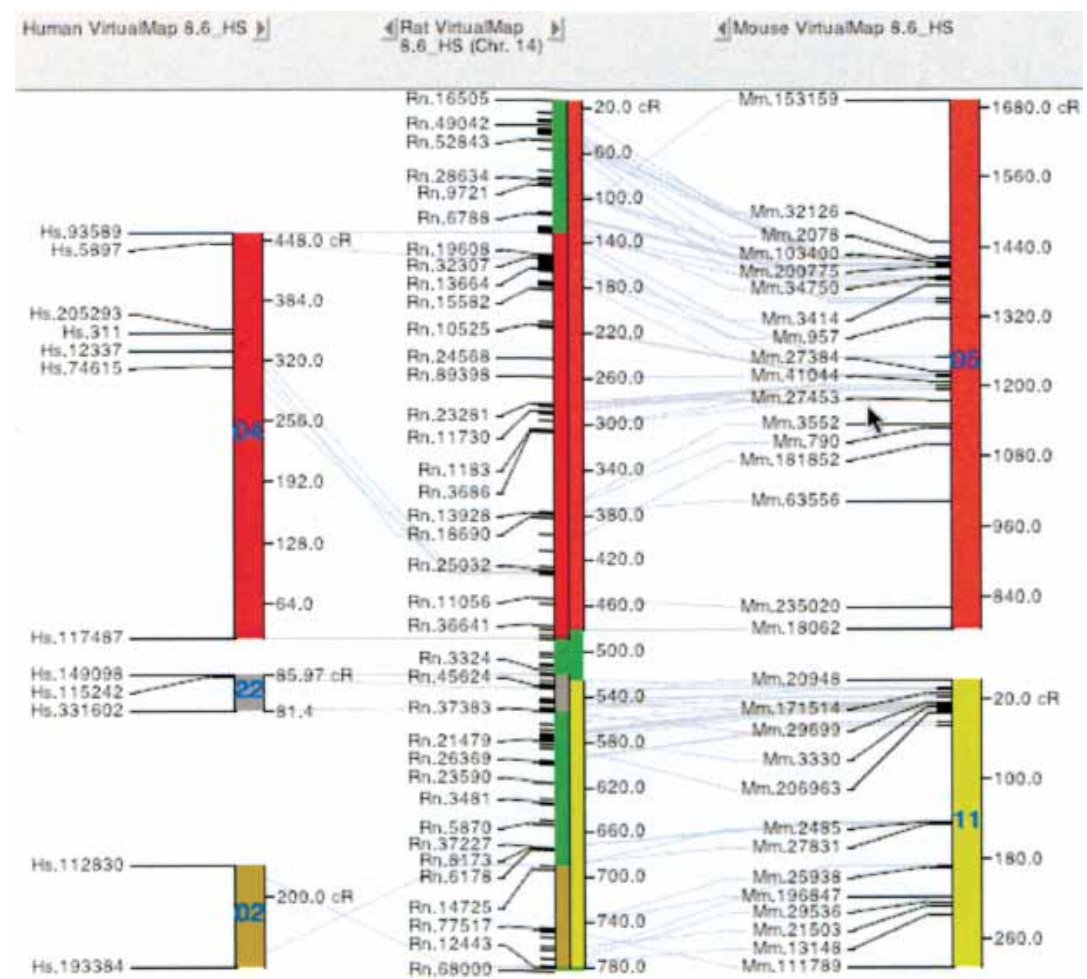

Figure 2 Display of rat Chr 14 (center) and syntenic regions in human Chr 4, 22 and 2 (left) and mouse Chr 5 and 11 (right).
Mendelian Inheritance in Man (OMIM) and has $~ 9000$ genes documented to be involved in human disease.

\section{Integrative Genomics Environment}

Perhaps the most important result of collecting and integrating this extensive set of maps, data, and annotated comparison analyses from multiple organisms into one environment is the ability to conduct in silico experiments, "virtually" mapping experimental results from one organism onto another. This environment greatly expands the current view of comparative genomics by providing a platform for comparing, collecting, and referencing genetically linked annotations from one organism to that of another organism. Although this type of study is not new (for a review, see Stoll et al. 2000; Jacob and Kwitek 2002), previously it entailed a great deal of manual intervention, and hence, the ability to quickly compare mapped traits between multiple organisms in a single environment removes a significant barrier that has typically hindered the use of this comparative data. One example of this virtual experiment arises in the study of arthritis. The $\mathrm{q}$ terminal region of rat Chr10 contains QTLs associated with various forms of induced arthritis (oil-induced arthritis QTLs Oia3-6 [Lorentzen et al. 1998; Holm et al. 2001], collagen-induced arthritis QTLs Cia16, Cia20-23, Ciaa2 [Longman et al. 1996; Furuya et al. 2000; Joe et al. 2000]). Confidence in this region and the search for potential candidate genes would be significantly aided by knowledge of other supporting evidence from other organisms such as the mouse. By visualizing the rat QTLs aligned with the rat genome annotations and the rat and mouse comparative maps, this region is found to be syntenic to a portion of mouse Chr11. Aligning this syntenic region of mouse Chr11 with the dense mouse genome annotations and then with the MGI genetic map and its associated QTLs reveals four mouse arthritis QTLs in the syntenic region: Sle1 (systemic lupus erythematosus susceptibility 1; Morel et al. 1994), Bbaa4 (B. burgdorferi-associated arthritis 4; Weis et al. 1999), Orch3 (autoim-

\section{Genome Research} www.genome.org 


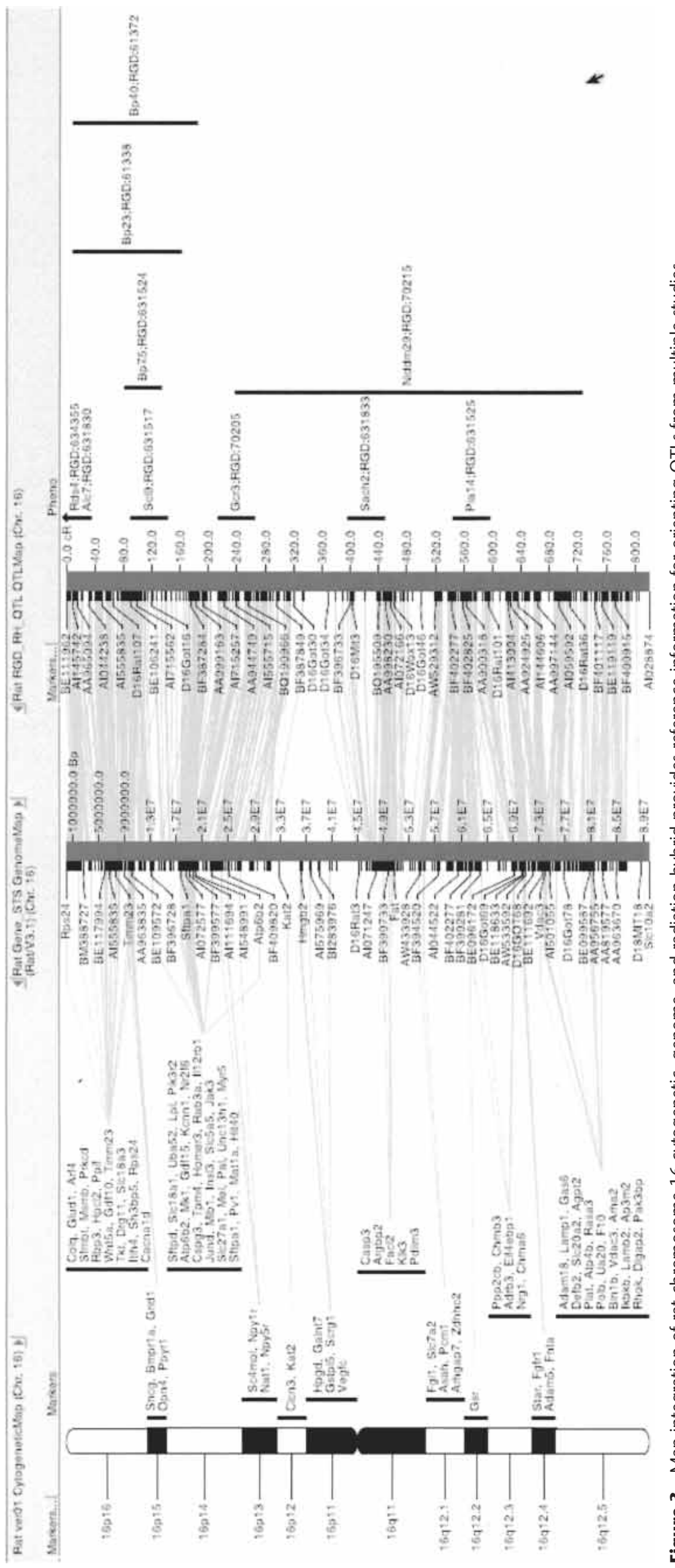

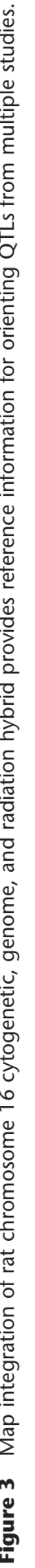


Twigger et al.

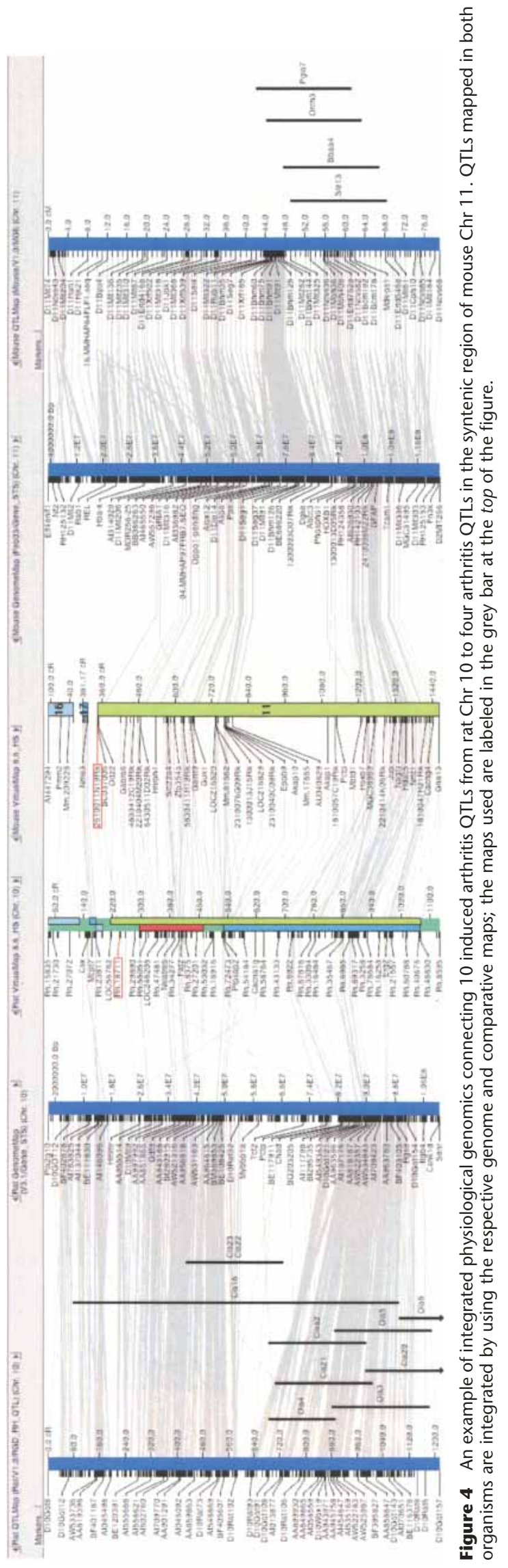

656 Genome Research

www.genome.org 
mune orchitis resistance 3; Meeker et al. 1995), and Pgia17 (proteoglycan induced arthritis QTL 7; Fig. 4; Otto et al. 1999). In this example we have efficiently traversed the data and integrative maps by using the IGE to conduct an in silico experiment, resulting in the association of QTLs derived from physiological experiments studying the same disease in mouse and rat models of arthritis. A review of the related literature from human linkage studies reveals that the syntenic region of human Chr 17 has also been associated with arthritis (Jawaheer et al. 2001, 2003), and in one case, this association was a direct result of using syntenic rat data (Barton et al. 2001). This supports the fundamental paradigm of comparative genomics, namely, that candidate genes in rat and mice models of arthritis may well be characterized by common syntenic location and homology with each other and that these results can be translated to human. If true, such characterizations greatly reduce the number of potential candidate genes for the disease.

\section{Integrated Maps In Silico}

VCMapView is a java-based tool that allows navigation between multiple genomes and within individual organisms by providing map integration between the cytogenetic, genetic, and RH maps and related genomic sequence contained within the IGE. VCMapview displays multiple maps from one or more organisms in the native coordinate system of each map and thus allows the comparative relationships between the maps to be explored on the fly. Visual anchor lines between shared objects (such as markers and genes) and the ability to highlight markers shared between maps aid map integration. Individual maps can be displayed as required, as can map units and the marker names. Additional annotations such as QTLs can be toggled on or off and, as with markers, are hyperlinked to database reports. Whereas the strength of the genome browsers is their ability to display very detailed annotation at a base-pair resolution, the strength of VCMapview is that such detailed annotations can be turned off, allowing a clearer view of an entire chromosome. VCMapview complements and greatly extends existing browsers and resources and includes a wide spectrum of functionality including zooming, cross-organism annotation, dynamic resizing, and orientation and on-the-fly visual modifications. An online help environment explains all features and options and user support is provided through the RGD support team.

\section{DISCUSSION}

The human, rat, and mouse genome projects require substantial analysis and interpretation to provide the detailed data and information required by an individual investigator exploring his or her respective mechanisms, phenotypes, and diseases. The Integrated Genomics Environment combines analysis, an extensive mapping database, and the VCMapView visualization tool to provide a resource allowing individuals to mine the depth and richness of the genomes. The future of physiological and clinical research will depend on the availability of such resources that will compare multiple maps within and between organisms. A map integration/comparative-mapping paradigm strategy (Fig. 1) demonstrates how to investigate a phenotype mapped onto the rat genome and exploit results from the human and mouse genomes. Currently, IGE represents the most comprehensive collection of cross-organism map data of any utility available to the research community. In particular, this is the largest collection of map and reference information for rat. An example of the integration of the data is presented in Figure 1 of Kwitek et al. 2004 (this issue) a visualization of the three major genetic, $\mathrm{RH}$, and genome maps used to curate and analyze the quality of the new rat $\mathrm{RH}$ map.

\section{Markers and Maps}

A total of 22 genetic, cytogenetic, RH maps, and related genome sequence have been integrated into the IGE database (for complete list, see Table 1). As a result of the marker curation activities of the RGD, this environment also provides the largest and most stringently reviewed collection of rat markers available. In total, 228,301 mapped markers from the three species are integrated into a single searchable cross-mapped environment, providing investigators with an enormously powerful search, exploration, and discovery resource.

\section{Intraorganism Maps}

IGE's VCMapView was also used to validate the new MCW RH map version 3.4 by performing a simultaneous viewing of new and old RH and genetic maps. Build and curation errors were easily detected at the genome level and directed the detailed error checking and validation. Figure 5 shows the two versions of the $\mathrm{RH}$ aligned and fundamentally similar, although rearrangement is observed in version 3.4 resulting from the increased marker density (Kwitek et al. 2004). This application of VCMapView was further used in initial evaluations of the rat genomic assemblies (R. Gibbs, pers. comm.). Visualization of genomic map build(s) alongside the RH map identified assembly divergence between builds (Fig. 6) This is the first environment that integrates genomic sequence with cytogenetic, $\mathrm{RH}$, and genetic maps, enabling integration of individual genome study results from previous work to be associated with the genome sequence.

\section{Integrative Map Browser}

Our earlier results provided static views of comparative maps between rat, mouse, and human constructed from the respective RH maps combined with sequence-based homology with the

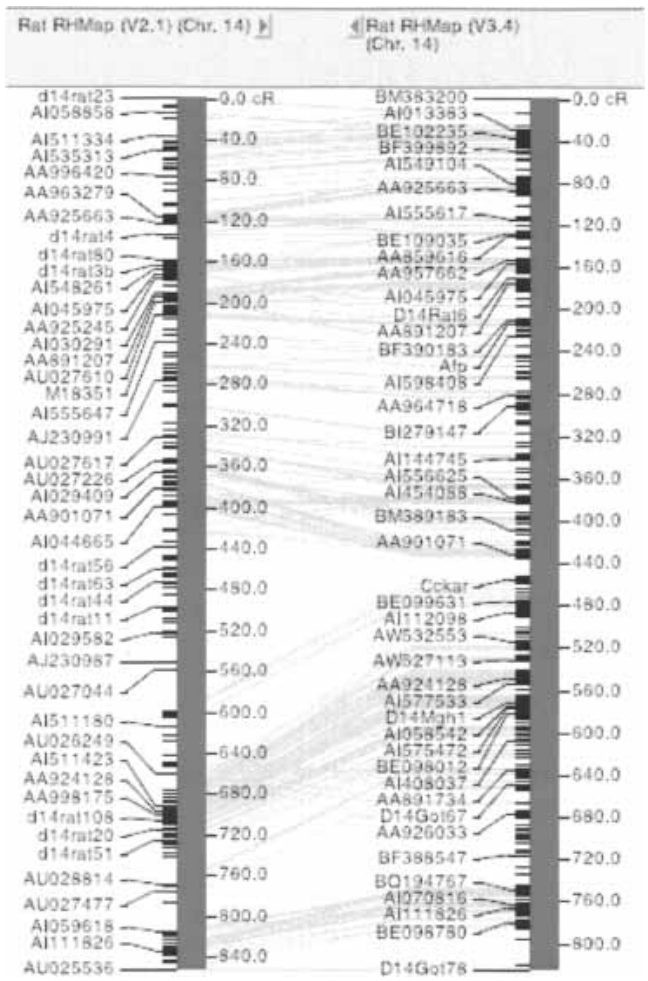

Figure 5 Functional alignment of updated release of the rat radiation hybrid map RH version 3.4 aligned with the original $\mathrm{RH}$ version 2.1 used for quality control. 


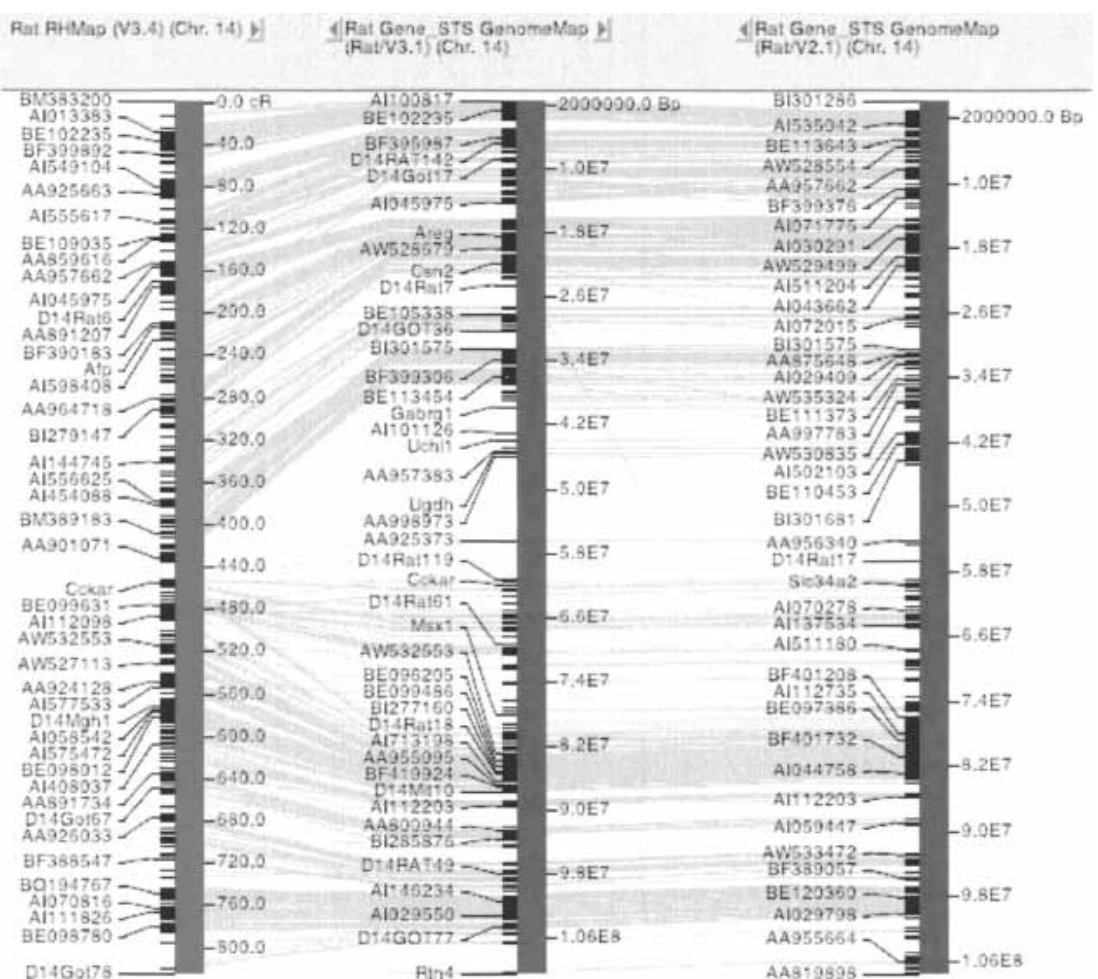

Figure 6 Current rat genome build (version 3.1) and earlier builds can be aligned with either genetic maps (data not shown), previous genome assemblies (version 2.1 shown), or the radiation hybrid map (RH 3.4) for overall review and quality control.

three organisms (Kwitek et al. 2001). These results and site supported the translation of rat QTLs to the RH map and to syntenic regions in human and/or mouse. However, the original static release required substantial manual effort to update and use and did not include important cytogenetic and genetic data, or reference to rat genome sequence. VCMapView overcomes these manual bottlenecks and provides investigators with a powerful tool to perform in silico physiological comparative mapping experiments, thus translating results from one organism to another and at the same time connecting the powerful approach to complex disease modeling in the rat, to the genetics of the mouse, and the clinical importance of human.

\section{Integrative Genomics Environment}

To create a unified display for all the QTLs, flanking markers were located on the rat genome 3.1 build and the rat RH 3.4 maps, and these locations were then used to position the QTLs relative to the genome. Similarly, the MGD has 1461 available QTLs linked to the MGI genetic map, and both the map and the associated QTLs were loaded into IGE for concurrent display and review of large collections of genomic annotations. The dynamic integration of maps and associated QTLs of multiple organisms allows the comparison of QTL locations between genomes (Fig. 4). In the example discussed in the Results section, 10 rat QTLs associated with induced arthritis on rat Chr 10 are integrated with mouse Chr 11, which also contains four QTLs for related arthritic phenotypes. This observation leads to a hypothesis relating homology of candidate genes in the syntenic regions as more likely candidates for the genes important to arthritis.

The IGE allows in silico research supporting new hypothesis development and testing. In providing a comprehensive collection of marker and map data from the three species and a visualization tool that allows the intra- and intergenome compari- sons, IGE is a uniquely valuable tool for data integration within organisms and for comparative genomics studies between organisms.

\section{METHODS}

\section{Data Sources}

All published maps contained within the IGE are listed in Table 1 along with citations listing the sources for the mapping data. Four of the annotation data sets included in IGE have not been published, and they were created as follows.

\section{Rat Genome}

An annotation data set was MCW annotation of rat genome build 3.1. Sequences contained within the RGD (all available on the RGD FTP site) were used in the annotation of the genome build, using standard annotation tools. Gene RefSeqs and Sequence Tag Site (Microsatellite and ESTs) primer and clone sequences were used in ePCR and BLAT analyses to localize RGD objects to the rat genome. Objects that mapped to a unique location were retained, and their mapping data used in the creation of the annotation data set.

\section{Rat Cytogenetic Map}

Data was obtained from Ratmap (Ratmap), LocusLink (http://www.ncbi.nih.gov/ LocusLink/), and RGD (http://rgd.mcw.edu) mapping databases. Genes mapped by FISH or similar experimental procedures were obtained from Ratmap and located on the genome 3.1 build. These known cytogenetic band locations were used as a framework to define cytogenetic "bins," thereby allowing the band locations to be predicted for the nonexperimentally mapped genes mapped to the genome within the bin defined by the "framework" markers. Currently, the experimental and predicted genes are not distinguished on the visualization, although work is in progress to address this.

\section{Rat QTL Maps}

QTL mapping data was obtained from the RGD QTL FTP file (http://rgd.mcw.edu/pub/data_release/QTLS) and consists of curated flanking and peak markers defining the limits and center of a QTL region, respectively. The marker information was then combined with mapping data from a particular map in order to position QTLs originally mapped on many individual genetic maps onto a single unified map. Because not all flanking and peak markers are present on a single map, various interpolation strategies were used to place QTLs with incomplete mapping data. Four scenarios were encountered: (1) at least both flanking markers are mapped-this is the ideal situation and the QTL region was defined by the map locations of the two flanking markers; (2) only the peak marker is mapped-the center of the QTL is known but the span is unknown (in these cases the size of the QTL was set to a default conservative value based on the average QTL size of QTLs for which both flanking markers were mapped-50 Mb on genome maps, $298 \mathrm{cR}$ on $\mathrm{RH}$ - and centered on the peak marker's location); (3) one flanking marker and the peak marker are mapped-in this case the QTL was assumed to be symmetrical and the other flank predicted to lie on the opposite side of the peak marker and the same distance away from the peak as the one mapped flanking marker; and (4) only one flanking marker was mapped-in these cases insufficient information was available to place the QTL on the map, and these QTLs are not shown on the QTL maps. 


\section{Mouse QTL Maps}

QTL mapping data was obtained from the MGD (http: //informatics.jax.org) along with mapping data for the peak of the QTL based on the MGD consensus genetic map. As no flanking marker data were readily available defining the borders of the QTL regions, a standard QTL width of $20 \mathrm{cM}$ was used centered at the map location of the QTL peak.

\section{VCMapView}

VCMapView is based on GDB mapview, a java applet codebase (Letovsky et al. 1998), and was modified to create the functionality and features to produce a genome-wide, cross-organism, multimap dynamic browser. It is available on the RGD (http: //rgd.mcw.edu/VCMAP/). IGE mapping data used by VCMapView is stored in a Berkeley DB binary format to facilitate data retrieval, greatly enhancing performance over standard flat files or relational database storage. VCMapView is unique among genome visualization tools in that most of these tools use a technology (common gateway interface, CGI) that precludes dynamic displays as regions, organisms, and maps are revised and aligned. The screen refresh requirements of CGI technology in practice limits the portions of the genome/chromosome manipulated and viewed. Another current limitation of the browsers is that all results must be referenced to a single genome; consequently, displaying syntenic regions necessitates a visual compromise to expand or contract the aligned genome(s). Similarly, vertical visual "anchor" or reference lines are not available, making the representation of different maps in a single genome browser virtually impossible. A future version of the GMOD Gbrowse tool may provide this functionality, thus allowing comparative data to be viewed (L. Stein, pers. comm.). NCBI's Map viewer is a CGI browser with vertical orientation that can display a variety of different maps, thereby allowing integration. Benefiting from tight integration with NCBI resources, it has recently been updated to display syntenic regions.

\section{ACKNOWLEDGMENTS}

We would like to acknowledge the RGD bioinformatics and curation teams for their great contributions to the collection and validation of map data and for contributions to VCMapView testing and integration into the RGD environment, as well as past and present members of the S.N.T., H.J.J., and P.J.T. groups for their technical assistance. Thank you to Mike Jensen-Seaman for providing the photograph of the Brown Norway rat used in Figure 1. VCMapView is licensed to PointOne Systems, LLC, Milwaukee, WI. All data integrated into the tool is publicly available. This work has been supported by RO1s HL59826 (H.J.J.), HL54508, HL066579 (H.J.J.), HL54998, and HL64541 (P.J.T.).

The publication costs of this article were defrayed in part by payment of page charges. This article must therefore be hereby marked "advertisement" in accordance with 18 USC section 1734 solely to indicate this fact.

\section{REFERENCES}

al-Majali, K.M., Glazier, A.M., Norsworthy, P.J., Wahid, F.N., Cooper, L.D., Wallace, C.A., Scott, J., Lausen, B., and Aitman, T.J. 1999. A high-resolution radiation hybrid map of the proximal region of rat chromosome 4. Mamm. Genome 10: 471-476.

Avner, P., Bruls, T., Poras, I., Eley, L., Gas, S., Ruiz, P., Wiles, M.V., Sousa-Nunes, R., Kettleborough, R., Rana, A., et al. 2001. A radiation hybrid transcript map of the mouse genome. Nat. Genet. 29: 194-200.

Barton, A., Eyre, A., Myerscough, A., Brintnell, B., Ward, D., Ollier, W.E., Lorentzen, J.C., Klareskog, L., Silman, A., John, S., et al. 2001 High resolution linkage and association mapping identifies a novel rheumatoid arthritis susceptibility locus homologous to one linked to two rat models of inflammatory arthritis. Hum. Mol. Genet. 10: $1901-1906$.

Behboudi, A., Roshani, L., Kost-Alimova, M., Sjostrand, E. Montelius-Alatalo, K., Rohme, D., Klinga-Levan, K., and Stahl, F. 2002. Detailed chromosomal and radiation hybrid mapping in the proximal part of rat chromosome 10 and gene order comparison with mouse and human. Mamm. Genome 13: 302-309.
Bihoreau, M.T., Sebag-Montefiore, L., Godfrey, R.F., Wallis, R.H., Brown, J.H., Danoy, P.A., Collins, S.C., Rouard, M., Kaisaki, P.J., Lathrop, M., et al. 2001. A high-resolution consensus linkage map of the rat, integrating radiation hybrid and genetic maps. Genomics 75: 57-69.

Blake, J.A., Richardson, J.E., Bult, C.J., Kadin, J.A., and Eppig, J.T. 2003. MGD: The Mouse Genome Database. Nucleic Acids Res. 31: 193-195.

Broman, K.W., Murray, J.C., Sheffield, V.C., White, R.L., and Weber, J.L. 1998. Comprehensive human genetic maps: Individual and sex-specific variation in recombination. Am. J. Hum. Genet. 63: 861-869.

Brown, D.M., Matise, T.C., Koike, G., Simon, J.S., Winer, E.S., Zangen, S., McLaughlin, M.G., Shiozawa, M., Atkinson, O.S., Hudson Jr., J.R., et al. 1998. An integrated genetic linkage map of the laboratory rat. Mamm. Genome 9: 521-530.

Clamp, M., Andrews, D., Barker, D., Bevan, P., Cameron, G., Chen, Y. Clark, L., Cox, T., Cuff, J., Curwen, V., et al. 2003. Ensembl 2002: Accommodating comparative genomics. Nucleic Acids Res. 31: 38-42.

Couronne, O., Poliakov, A., Bray, N., Ishkhanov, T., Ryaboy, D., Rubin, E., Pachter, L., and Dubchak, I. 2003. Strategies and tools for whole-genome alignments. Genome Res. 13: 73-80.

Cox, D.R., Burmeister, M., Price, E.R., Kim, S., and Myers, R.M. 1990 Radiation hybrid mapping: A somatic cell genetic method for constructing high-resolution maps of mammalian chromosomes. Science 250: 245-250.

Deloukas, P., Schuler, G.D., Gyapay, G., Beasley, E.M., Soderlund, C., Rodriguez-Tome, P., Hui, L., Matise, T.C., McKusick, K.B., Beckmann, J.S., et al. 1998. A physical map of 30,000 human genes. Science 282: 744-746.

Dib, C., Faure, S., Fizames, C., Samson, D., Drouot, N., Vignal, A., Millasseau, P., Marc, S., Hazan, J., Seboun, E., et al. 1996. A comprehensive genetic map of the human genome based on 5,264 microsatellites. Nature 380: 152-154.

Dobbins, D.E., Joe, B., Hashiramoto, A., Salstrom, J.L., Dracheva, S., Ge, L., Wilder, R.L., and Remmers, E.F. 2002. Localization of the mutation responsible for osteopetrosis in the op rat to a 1.5-cM genetic interval on rat chromosome 10: Identification of positional candidate genes by radiation hybrid mapping. J. Bone Miner Res. 17: 1761-1767.

Dracheva, S.V., Remmers, E.F., Chen, S., Chang, L., Gulko, P.S., Kawahito, Y., Longman, R.E., Wang, J., Du, Y., Shepard, J., et al. 2000. An integrated genetic linkage map with 1137 markers constructed from five F2 crosses of autoimmune disease-prone and -resistant inbred rat strains. Genomics 63: 202-226.

Furuya, T., Salstrom, J.L., McCall-Vining, S., Cannon, G.W., Joe, B., Remmers, E.F., Griffiths, M.M., and Wilder, R.L. 2000. Genetic dissection of a rat model for rheumatoid arthritis: Significant gender influences on autosomal modifier loci. Hum. Mol. Genet. 9: 2241-2250.

Gosele, C., Hong, L., Kreitler, T., Rossmann, M., Hieke, B., Gross, U., Kramer, M., Himmelbauer, H., Bihoreau, M.T., Kwitek-Black, A.E., et al. 2000. High-throughput scanning of the rat genome using interspersed repetitive sequence-PCR markers. Genomics 69: 287-294.

Holm, B.C., Xu, H.W., Jacobsson, L., Larsson, A., Luthman, H., and Lorentzen, J.C. 2001. Rats made congenic for Oia3 on chromosome 10 become susceptible to squalene-induced arthritis. Hum. Mol. Genet. 10: 565-572.

Hornum, L. and Markholst, H. 2000. Comparative mapping of the human homologue of the rat diabetes susceptibility gene lyp to a 1.3-Mb segment on HSA7. Genomics 65: 81-83.

Hudson, T.J., Church, D.M., Greenaway, S., Nguyen, H., Cook, A., Steen, R.G., Van Etten, W.J., Castle, A.B., Strivens, M.A., Trickett, P., et al. 2001. A radiation hybrid map of mouse genes. Nat. Genet. 29: 201-205.

Jacob, H.J. and Kwitek, A.E. 2002. Rat genetics: Attaching physiology and pharmacology to the genome. Nat. Rev. Genet. 3: 33-42.

Jawaheer, D., Seldin, M.F., Amos, C.I., Chen, W.V., Shigeta, R., Monteiro, J., Kern, M., Criswell, L.A., Albani, S., Nelson, J.L., et al. 2001. A genomewide screen in multiplex rheumatoid arthritis families suggests genetic overlap with other autoimmune diseases. Am. J. Hum. Genet. 68: 927-936.

Jawaheer, D., Seldin, M.F., Amos, C.I., Chen, W.V., Shigeta, R., Etzel, C., Damle, A., Xiao, X., Chen, D., Lum, R.F., et al. 2003. Screening the genome for rheumatoid arthritis susceptibility genes: A replication study and combined analysis of 512 multicase families. Arthritis Rheum. 48: 906-916.

Joe, B., Remmers, E.F., Dobbins, D.E., Salstrom, J.L., Furuya, T., Dracheva, S., Gulko, P.S., Cannon, G.W., Griffiths, M.M., and Wilder, R.L. 2000. Genetic dissection of collagen-induced arthritis in chromosome 10 quantitative trait locus speed congenic rats: Evidence for more than one regulatory locus and sex influences. Immunogenetics 51: 930-944.

Kaisaki, P.J., Rouard, M., Danoy, P.A., Wallis, R.H., Collins, S.C., Rice, M., Levy, E.R., Lathrop, M., Bihoreau, M.T., and Gauguier, D. 2000. Detailed comparative gene map of rat chromosome 1 with mouse and human genomes and physical mapping of an evolutionary chromosomal breakpoint. Genomics 64: 32-43. 
Karolchik, D., Baertsch, R., Diekhans, M., Furey, T.S., Hinrichs, A., Lu, Y.T., Roskin, K.M., Schwartz, M., Sugnet, C.W., Thomas, D.J., et al. 2003. The UCSC Genome Browser Database. Nucleic Acids Res. 31: 51-54.

Kitada, K., Voigt, B., Kondo, Y., and Serikawa, T. 2000. An integrated rat genome map based on genetic and cytogenetic data. Exp. Anim. 49: $119-126$.

Kuroiwa, A., Watanabe, T., Hishigaki, H., Takahashi, E., Namikawa, T., and Matsuda, Y. 1998. Comparative FISH mapping of mouse and rat homologues of 25 human X-linked genes. Cytogenet. Cell. Genet. 81: 208-212.

Kwitek, A.E., Tonellato, P.J., Chen, D., Gullings-Handley, J., Cheng, Y.S., Twigger, S., Scheetz, T.E., Casavant, T.L., Stoll, M., Nobrega, M.A., et al. 2001. Automated construction of high-density comparative maps between rat, human, and mouse. Genome Res. 11: 1935-1943.

Kwitek, A.E., Gullings-Handley, J., Yu, J., Carlos, D.C., Orlebeke, K., Nie, J., Eckert, J., Lemke, A., Andrae, J.W., Bloomberg, S., et al. 2004 High-density rat radiation hybrid maps containing over 24,000 SSLPs, genes, and ESTs provide a direct link to the rat genome sequence. Genome Res. (this issue).

Laes, J.F., Ravoet, M., Quan, X., Van Vooren, P., Szpirer, J., and Szpirer, C. 2001. Improved radiation hybrid map of rat chromosome 2: Colocalization of the genes encoding corticotropin-releasing hormone and IL6-receptor with quantitative trait loci regulating the inflammatory response. Cytogenet. Cell Genet. 92: 130-133.

Letovsky, S.I., Cottingham, R.W., Porter, C.J., and Li, P.W. 1998. GDB: The Human Genome Database. Nucleic Acids Res. 26: 94-99.

Longman, R.E., Remmers, E.F., Cannon, G., Griffiths, M., and Wilder, R.L. 1996. Localization of genetic loci controlling antibody response to autologous collagen in rats with collagen-induced arthritis (Cia). Arthritis Rheum. 39: S117.

Lorentzen, J.C., Glaser, A., Jacobsson, L., Galli, J., Fakhrai-rad, H., Klareskog, L., and Luthman, H. 1998. Identification of rat susceptibility loci for adjuvant-oil-induced arthritis. Proc. Natl. Acad. Sci. 95: 6383-6387.

Marino, M.W., Fuller, G.M., and Elder, F.F. 1986. Chromosomal localization of human and rat $\mathrm{A} \alpha, \mathrm{B} \beta$, and $\gamma$ fibrinogen genes by in situ hybridization. Cytogenet. Cell Genet. 42: 36-41.

McCarthy, L.C., Bihoreau, M.T., Kiguwa, S.L., Browne, J., Watanabe, T.K., Hishigaki, H., Tsuji, A., Kiel, S., Webber, C., Davis, M.E., et al. 2000. A whole-genome radiation hybrid panel and framework map of the rat genome. Mamm. Genome 11: 791-795.

McKusick, V.A. and Amberger, J.S. 1993. The morbid anatomy of the human genome: Chromosomal location of mutations causing disease. J. Med. Genet. 30: 1-26.

Meeker, N.D., Hickey, W.F., Korngold, R., Hansen, W.K., Sudweeks, J.D., Wardell, B.B., Griffith, J.S., and Teuscher, C. 1995. Multiple loci govern the bone marrow-derived immunoregulatory mechanism controlling dominant resistance to autoimmune orchitis. Proc. Natl. Acad. Sci. 92: 5684-5688.

Morel, L., Rudofsky, U.H., Longmate, J.A., Schiffenbauer, J., and Wakeland, E.K. 1994. Polygenic control of susceptibility to murine systemic lupus erythematosus. Immunity 1: 219-229.

Nilsson, S., Helou, K., Walentinsson, A., Szpirer, C., Nerman, O., and Stahl, F. 2001. Rat-mouse and rat-human comparative maps based on gene homology and high-resolution zoo-FISH. Genomics 74: 287-298.

Otto, J.M., Cs-Szabo, G., Gallagher, J., Velins, S., Mikecz, K., Buzas, E.I. Enders, J.T., Li, Y., Olsen, B.R., and Glant, T.T. 1999. Identification of multiple loci linked to inflammation and autoantibody production by a genome scan of a murine model of rheumatoid arthritis. Arthritis Rheum. 42: 2524-2531.

Rapp, J.P. 2000. Genetic analysis of inherited hypertension in the rat. Physiol. Rev. 80: 135-172.

Remmers, E.F., Griffiths, M.M., Longman, R.E., Gulko, P.S., Kawahito, Y., Chen, S., Chang, L., Shepard, J., Ge, L., Dracheva, S., et al. 1999. An integrated rat genetic map: Analysis of linkage conservation with the mouse and human maps. Transplant Proc. 31: 1549-1554.

Scheetz, T.E., Raymond, M.R., Nishimura, D.Y., McClain, A., Roberts, C., Birkett, C., Gardiner, J., Zhang, J., Butters, N., Sun, C., et al. 2001. Generation of a high-density rat EST map. Genome Res. 11: 497-502.

Schulz, A., Marquardt, H., Szpirer, J., Szpirer, C., and Kreutz, R. 2000. Assignment of the genes encoding nephrin (Nphs1) and $\alpha$-actinin 4 (Actn4) to rat chromosome 1q22 by in situ hybridization and radiation hybrid mapping. Cytogenet. Cell Genet. 90: 337-338.

Schwartz, S., Zhang, Z., Frazer, K.A., Smit, A., Riemer, C., Bouck, J., Gibbs, R., Hardison, R., and Miller, W. 2000. PipMaker: A Web server for aligning two genomic DNA sequences. Genome Res. 10: 577-586.

Serikawa, T., Cui, Z., Yokoi, N., Kuramoto, T., Kondo, Y., Kitada, K., and Guenet, J.L. 1998. A comparative genetic map of rat, mouse and human genomes. Exp. Anim. 47: 1-9.

Steen, R.G., Kwitek-Black, A.E., Glenn, C., Gullings-Handley, J., Van Etten, W., Atkinson, O.S., Appel, D., Twigger, S., Muir, M., Mull, T., et al. 1999. A high-density integrated genetic linkage and radiation hybrid map of the laboratory rat. Genome Res. 9: AP1-8, insert.

Stein, L.D., Mungall, C., Shu, S., Caudy, M., Mangone, M., Day, A., Nickerson, E., Stajich, J.E., Harris, T.W., Arva, A., et al. 2002. The generic genome browser: A building block for a model organism system database. Genome Res. 12: 1599-1610.

Stoll, M., Kwitek-Black, A.E., Cowley Jr., A.W., Harris, E.L., Harrap, S.B. Krieger, J.E., Printz, M.P., Provoost, A.P., Sassard, J., and Jacob, H.J. 2000. New target regions for human hypertension via comparative genomics. Genome Res. 10: 473-482.

Szpirer, J., Levan, G., Thorn, M., and Szpirer, C. 1984. Gene mapping in the rat by mouse-rat somatic cell hybridization: Synteny of the albumin and $\alpha$-fetoprotein genes and assignment to chromosome 14. Cytogenet. Cell. Genet. 38: 142-149.

Szpirer, C., Riviere, M., Szpirer, J., Genet, M., Dreze, P., Islam, M.Q., and Levan, G. 1990. Assignment of 12 loci to rat chromosome 5: Evidence that this chromosome is homologous to mouse chromosome 4 and to human chromosomes 9 and 1 (1p arm). Genomics 6: 679-684.

Szpirer, C., Szpirer, J., Tissir, F., Stephanova, E., Vanvooren, P., Kurtz, T.W., Iwai, N., Inagami, T., Pravenec, M., Kren, V., et al. 1997. Rat chromosome 1: Regional localization of seven genes (Slc9a3, Srd5a1, Esr, Tcp1, Grik5, Tnnt3, Jak2) and anchoring of the genetic linkage map to the cytogenetic map. Mamm. Genome 8: 657-660.

Szpirer, C., Szpirer, J., Van Vooren, P., Tissir, F., Simon, J.S., Koike, G., Jacob, H.J., Lander, E.S., Helou, K., Klinga-Levan, K., et al. 1998. Gene-based anchoring of the rat genetic linkage and cytogenetic maps: New regional localizations, orientation of the linkage groups, and insights into mammalian chromosome evolution. Mamm. Genome 9: 721-734.

1999. Gene-based anchoring of the rat genetic linkage and cytogenetic maps. Transplant Proc. 31: 1541-1543.

Szpirer, C., Van Vooren, P., Riviere, M., Scohy, S., Collau, G., and Szpirer, J. 2000. Localization of 54 rat genes, and definition of new synteny groups conserved in the human and the rat. Mamm. Genome 11: 729-735.

Szpirer, C., Kas, K., Laes, J.F., Riviere, M., Van Vooren, P., and Szpirer, J. 2001. Assignment of the rat pleiomorphic adenoma genes (Plag1, Plagl1, Plag12) by in situ hybridization and radiation hybrid mapping. Cytogenet. Cell. Genet. 94: 94-95.

Tseng, J., Kwitek-Black, A.E., Erbe, C.B., Popper, P., Jacob, H.J., and Wackym, P.A. 2001. Radiation hybrid mapping of $11 \alpha$ and $\beta$ nicotinic acetylcholine receptor genes in Rattus norvegicus. Brain Res. Mol. Brain Res. 91: 169-173.

Tseng, J., Erbe, C.B., Kwitek, A.E., Jacob, H.J., Popper, P., and Wackym, P.A. 2002. Radiation hybrid mapping of five muscarinic acetylcholine receptor subtype genes in Rattus norvegicus. Hear Res. 174: 86-92.

Twigger, S., Lu, J., Shimoyama, M., Chen, D., Pasko, D., Long, H., Ginster, J., Chen, C.F., Nigam, R., Kwitek, A., et al. 2002. Rat Genome Database (RGD): Mapping disease onto the genome. Nucleic Acids Res. 30: 125-128.

Wallace, C.A., Ali, S., Glazier, A.M., Norsworthy, P.J., Carlos, D.C., Scott, J., Freeman, T.C., Stanton, L.W., Kwitek, A.E., and Aitman, T.J. 2002 Radiation hybrid mapping of 70 rat genes from a data set of differentially expressed genes. Mamm. Genome 13: 194-197.

Watanabe, T.K., Bihoreau, M.T., McCarthy, L.C., Kiguwa, S.L., Hishigaki, H., Tsuji, A., Browne, J., Yamasaki, Y., Mizoguchi-Miyakita, A., Oga, K., et al. 1999. A radiation hybrid map of the rat genome containing 5255 markers. Nat. Genet. 22: 27-36.

Weis, J.J., McCracken, B.A., Ma, Y., Fairbairn, D., Roper, R.J., Morrison, T.B., Weis, J.H., Zachary, J.F., Doerge, R.W., and Teuscher, C. 1999. Identification of quantitative trait loci governing arthritis severity and humoral responses in the murine model of Lyme disease. $J$. Immunol. 162: 948-956.

Yamada, J., Kuramoto, T., and Serikawa, T. 1994. A rat genetic linkage map and comparative maps for mouse or human homologous rat genes. Mamm. Genome 5: 63-83.

\section{WEB SITE REFERENCES}

http://rgd.mcw.edu; Rat Genome Databank. http://rgd.mcw.edu/VCMAP; VCMapView tool.

http://rgd.mcw.edu/tu/vmcap; VCMap help documentation. http://rgd.mcw.edu/RHMAPSERVER; RGD Radiation hybrid Mapserver. http://ratmap.gen.gu.se; Ratmap Database.

http://ratmap.ims.u-tokyo.ac.jp/cgi-bin/RH/rhNgv.pl; Otsuka RH Mapserver.

http://www.ncbi.nlm.nih.gov/mapview/static/MVstart.html; NCBI Map viewer.

http://www.genboree.org; Genboree.

http://informatics.jax.org; Mouse Genome Database.

Received September 13, 2003; accepted in revised form December 27, 2003.

\section{Genome Research}




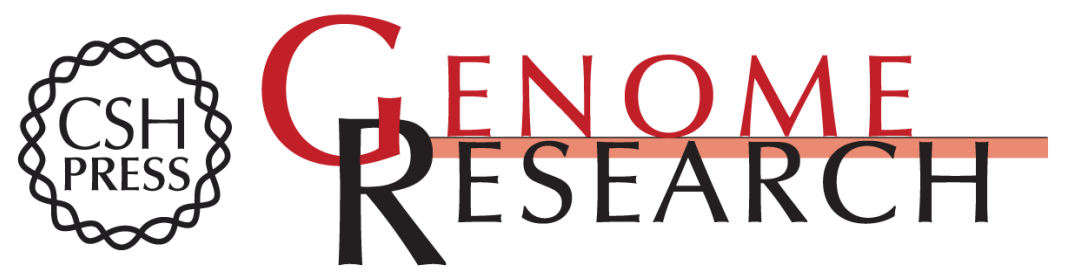

\section{Integrative Genomics: In Silico Coupling of Rat Physiology and Complex Traits With Mouse and Human Data}

Simon N. Twigger, Jeff Nie, Victor Ruotti, et al.

Genome Res. 2004 14: 651-660

Access the most recent version at doi:10.1101/gr.1974504

References This article cites 62 articles, 12 of which can be accessed free at:

http://genome.cshlp.org/content/14/4/651.full.html\#ref-list-1

\section{License}

Email Alerting Receive free email alerts when new articles cite this article - sign up in the box at the Service top right corner of the article or click here.

\section{Affordable, Accurate Sequencing.}

